\title{
Aranei, Lycosidae in Coal Open Pit Dump Ecosystem in Kuzbass
}

\author{
Laimonas Trilikauskas ${ }^{1, *}$, and Sergey Luzyanin ${ }^{2}$ \\ ${ }^{1}$ Institute of Systematics and Ecology of Animals, Siberian Branch of the Russian Academy of \\ Sciences, 630091, 11 Frunze str., Novosibirsk, Russian Federation \\ ${ }^{2}$ Kemerovo State University, 650000, 6 Krasnaya str., Kemerovo, Russian Federation
}

\begin{abstract}
Using one of the Kuzbass coal mines as an example, it is shown that Lycosidae is the most important group of spiders that settles in reclaimed dumps at the early stages of overgrowing. The most common and widespread wolf spiders on the dumps are Alopecosa accentuata, Alopecosa cuneata, and Xerolycosa miniata. The maximum of species diversity and dynamic density was discovered on the slope of the 15 -yearold dump, where 14 species of Lycosidae were observed, and the dynamic density reached almost 300 specimens per 100 trap-days. The greatest number of the family Lycosidae spiders' species occurred on the differentaged slopes of dumps at the end of June, while on the terraces - in the first half of June. The highest dynamic density of wolf spiders on the slopes and terraces of the reclaimed dumps has been registered in the second half of June. It was close to 300 specimens per 100 trap-days on the slope of the 15 -year-old dump. This parameter was more stable and had a bigger value at the control area in early August than on the slopes and terraces of the dumps.
\end{abstract}

\section{Introduction}

Kuznetsk coal basin (Kuzbass) is one of the world's largest coalfields. The coal basin is located mainly in the central part of the Kemerovo region between the mountain provinces of the Kuznetsk-Salair mountainous region: Kuznetsky Alatau in the east, Gornaya Shoria in the south and Salair Ridge in the west. Due to the open (career) method of minerals excavating, considerable areas have been occupied by coal dumps, which are extreme examples of natural ecosystems and landscapes transformation. There is the acute issue of the reclamation of lands disturbed by anthropogenic impact in the region, and recultivation is actively pursued. Problems of recovering processes' research and research of the various stages' features of succession at the coal mining sites are becoming increasingly urgent in the region. One of the most important branches of this research is the study of the technogenic factors' influence on faunal complexes and the population of various groups of invertebrates which could indicate a state of both natural and artificially transformed ecosystems [1-3].

There have been carried out relatively few studies in Siberia of how the coal mining

\footnotetext{
${ }^{*}$ Corresponding author: laimont@mail.ru
} 
industry effects on various arthropods taxons [4-8]. Such studies are also scarce in other regions of the world $[9,10]$.

Spiders, as one of the most massive and diverse taxonomic groups of ground arthropods in temperate zones, deserve special attention as objects of these kinds of research. However, the issues of the coal industry's influence on their spatial distribution and dynamics have still been studied mainly in the coal-mining regions of Europe $[11,12]$. Wolf spiders (Lycosidae) is one of the largest families of spiders of the world's fauna. In forest and forest-steppe habitats of temperate zones, they form the basis of spiders and are notable for high taxonomic diversity. These are predominantly wandering spiders that have no permanent shelters, do not build net traps, and actively populate disturbed or newly formed habitats. Specimens of this taxonomic group can live in different environmental conditions and they mostly inhabit a relatively wide range of habitats. Taking all these facts into consideration, it allows admitting wolf spiders the most interesting group in terms of studying spiders' settling of reclaimed coal cut dumps.

The purpose of the study is to establish the main features of the structure and dynamics of the wolf spiders' population on recultivated coal cut dumps of different ages of the Krasnobrodsky coal mine in Kuzbass.

\section{Materials and Methods}

The material for the study was collected on the reclaimed dumps of the Krasnobrodsky coal mine (Kemerovo Region). The collection and quantification of spiders were carried out by soil traps from May 20 to June 25 and July 13 to August 14, 2013. The investigations were carried out on 5 sites: 1 - the slope of a 15-year-old blade $\left(54^{\circ} 17^{\prime} 04^{\prime \prime} \mathrm{N}, 86^{\circ} 42^{\prime} 08^{\prime \prime} \mathrm{E}\right), 2$ terrace of 15 -year-old heap $\left(54^{\circ} 17^{\prime} 11^{\prime \prime} \mathrm{N}, 86^{\circ} 42^{\prime} 14^{\prime \prime} \mathrm{E}\right), 3$ - slope of 30-year-old heap $\left(54^{\circ} 17^{\prime} 02^{\prime}\right.$ 'N, $\left.86^{\circ} 41^{\prime} 85^{\prime \prime} \mathrm{E}\right), 4-$ a terrace of a 30 -year dump (54ำ $\left.17^{\prime} 08^{\prime \prime} \mathrm{N}, 86^{\circ} 41^{\prime} 85^{\prime \prime} \mathrm{E}\right), 5-$ a control site wich is a birchwood surrounded by grassy-cereal meadows $\left(54^{\circ} 16^{\prime} 84^{\prime \prime} \mathrm{N}\right.$, $86^{\circ} 41^{\prime} 67^{\prime \prime}$ E). A detailed description of the sites is given in a previously published paper [5]. Each site exhibited 10 traps, which were inspected five times during the entire observation period: 2 June, 16 June, 25 June, 3 August and 14 August. In total, 680 trapdays were spent; 1597 individuals of spiders were counted, 897 of which belonged to the Lycosidae. Both adult and juvenile specimens were taken into account. The latter was determined by the family.

Dynamic density was expressed in the number of specimens per 100 trap-days (catchday). The degree of dominance was assessed by the method of M. Wozny [13]. According to this method, species with a percentage of more than $30 \%$ in the community or in the taxocene are superdominant, with a percentage of $10-30 \%$ are eudominants, $5.1-10 \%$ are dominants, $2.1-5$ are subdominants, $1.1-2 \%$ are recedents and with a percentage of less than $1 \%$ are subrecedents. In the dominant complexes species from superdominants to subdominants were included.

Calculation of Spearman's rank correlation coefficients and graphical constructions in the work were carried out using the STATISTICA package, version 6.1.

\section{Results and Discussion}

Coal reclaimed dumps of different ages are an example of habitats attractive to large stray spiders, such as Lycosides. As a result of the research, 20 species of wolf spiders belonging to 4 genera were identified on the dumps of the Krasnobrodsky coal mine and the control site. According to the taxonomic diversity, they exceed all other groups of spiders that occur in the research area. Along with specimens of the Gnaphosidae family, represented by 16 species, wolf spiders form the basis of the spiders' population on reclaimed dumps of 
different ages. Wolf spiders on the first site (Fig. 1), that is located on the slope of a 15year-old dump, were the most taxonomically varied and numerous. The technical and biological stages of reclamation were carried out at this site. It is characterized by a weak development of a grass stand (projective coverage is not more than $30 \%$ ), and woody and shrubby vegetation which distinguish it from other sites of study.
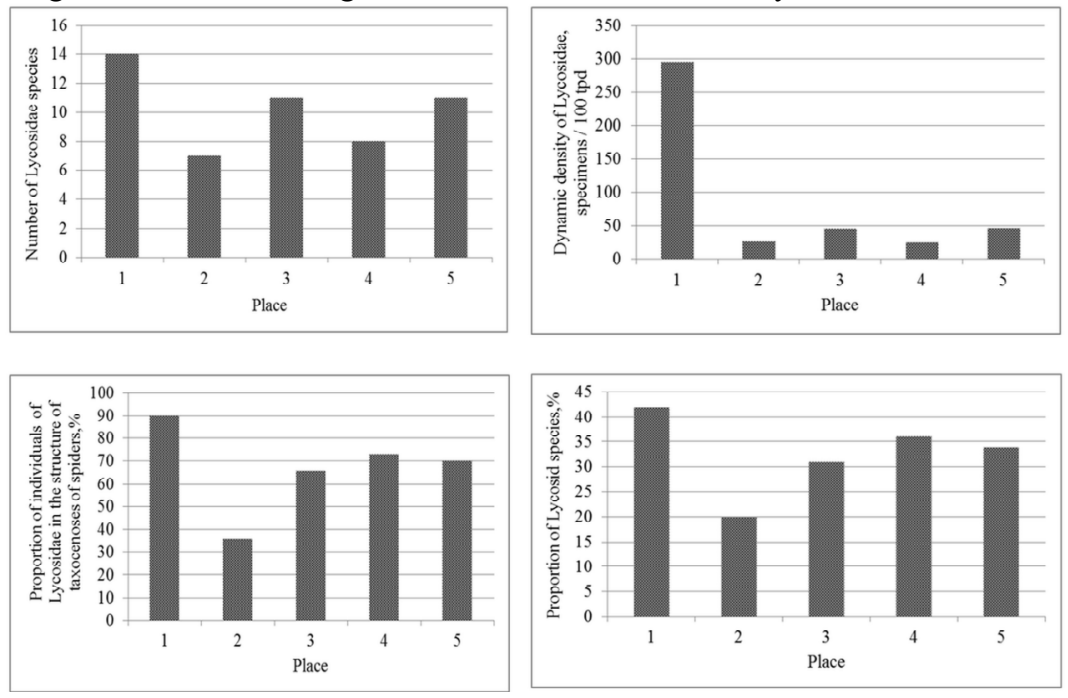

Fig. 1. Quantitative characteristics of the population of family Lycosidae spiders on coal dumps and control zone.

The dynamic density of Lycosides here reached a value close to 300 specimens per 100 catch-days, while in other areas, including the control one, it was below 50 specimens per 100 catch-days. The proportion of individuals and species of this family was the lowest in the second of the surveyed sites (Fig. 1), which is a terrace of the 15-year-old dump, covered with a forb meadow with a projective covering of grass cover $50-70 \%$ formed after two stages of reclamation [8]. It is remarkable to note that these parameters had similar values on the slope, the terrace of the 30 -year-old dump and the control site. In the first area both the proportion of individuals and the proportion of the species of the family in question had the highest values. According to the first parameter, wolf spiders here were absolute dominants among spiders. In general, it should be noted that in all the sites studied, except for the terrace of the 15-year-old dump, the proportion of wolf spiders exceeded $50 \%$, and the proportion of species of this family is $30 \%$.

There were calculated Spearman's rank correlation coefficients for the dynamic density and share in the overall taxocene structure between the specimens of the investigated family and the specimens of the ecologically closest group - stray spiders of the Gnaphosidae family for the entire time of observations on dumps (1-4 sites). A statistically significant positive correlation was found between the dynamic density of Lycosidae and Gnaphosidae (correlation coefficient $0.430561 \mathrm{p}<0.05$ ). The correlation between the percentage in the overall taxocene of specimens of these two families was also statistically significant, but negative (correlation coefficient $-0.626035 \mathrm{p}<0.05$ ). The inclusion of data from the control (5th site) in the analysis gives similar results at higher values of the correlation coefficients $(0.487204$ for the correlation by dynamic density and -0.665769 for the correlation in the proportion in the spiders' taxocene structure). Thus, changes in the dynamic density of these families' specimens subject to a similar pattern, while the dynamics of their percentage in the overall population structure is influenced by the 
dynamics of other taxa. With the growth of dynamic density, the percentage of specimens of one family in the population of spiders as a whole can decrease in individual terms, as a result, this parameter varies asynchronously in Lycosidae and Gnaphosidae.

The Table 1 shows the list of spiders of Lycosidae species, the degree of dominance of each species and their spatial distribution on the researched area (Note: $\mathrm{sr}$ - subrecedent, $\mathrm{r}-$ recedent, $\mathrm{sd}$ - subdominants, $\mathrm{d}$ - dominants, $\mathrm{e}$ - eudominants, $\mathrm{sp}$ - superdominants).

Table. Check-list, spatial distribution and degree of species dominance at the dumps of Krasnobrodsky coal mine and in a control zone.

\begin{tabular}{|l|c|c|c|c|c|}
\hline \multirow{2}{*}{ Species } & \multicolumn{5}{c|}{ Study sites } \\
\cline { 2 - 6 } & $\mathbf{1}$ & $\mathbf{2}$ & $\mathbf{3}$ & $\mathbf{4}$ & $\mathbf{5}$ \\
\hline Alopecosa accentuata (Latreille, 1817) & $\mathrm{Sr}$ & $\mathrm{r}$ & $\mathrm{Sd}$ & $\mathrm{sd}$ & $\mathrm{sd}$ \\
\hline Alopecosa cuneata (Celrck, 1758) & $\mathrm{Sd}$ & $\mathrm{sd}$ & $\mathrm{D}$ & $\mathrm{sr}$ & $\mathrm{e}$ \\
\hline Alopecosa cursor (Hahn, 1831) & & & $\mathrm{Sr}$ & & $\mathrm{sr}$ \\
\hline Alopecosa pulverulenta (Celrck, 1758) & & & $\mathrm{Sr}$ & & \\
\hline Alopecosa schmidti (Hahn, 1835) & & & $\mathrm{Sr}$ & & \\
\hline Alopecosa sulzeri (Pavesi, 1873) & & $\mathrm{sr}$ & & $\mathrm{sd}$ & $\mathrm{sr}$ \\
\hline Alopecosa cf. taeniopus (Kulczyński, 1895) & & & & & $\mathrm{sr}$ \\
\hline Alopecosa uiensis (Esyunin, 1996) & & & $\mathrm{sd}$ & $\mathrm{d}$ & $\mathrm{sd}$ \\
\hline Pardosa agrestis (Westring, 1861) & $\mathrm{Sp}$ & $\mathrm{sd}$ & & & $\mathrm{sr}$ \\
\hline Pardosa bifasciata (C. L. Koch, 1836) & $\mathrm{Sr}$ & $\mathrm{sr}$ & $\mathrm{sr}$ & $\mathrm{sr}$ & $\mathrm{sr}$ \\
\hline Pardosa fulvipes (Collett, 1875) & $\mathrm{R}$ & & $\mathrm{sr}$ & & \\
\hline Pardosa lasciva L. Koch, 1879 & $\mathrm{Sr}$ & & & & \\
\hline Pardosa cf. lugubris (Walckenar, 1802) & $\mathrm{Sr}$ & $\mathrm{e}$ & $\mathrm{sr}$ & $\mathrm{r}$ & $\mathrm{r}$ \\
\hline Pardosa paludicola (Celrck, 1758) & $\mathrm{R}$ & & & & \\
\hline Pardosa palustris (Linnaeus, 1758) & $\mathrm{Sr}$ & & & & \\
\hline Pardosa prativaga (L. Koch, 1870) & $\mathrm{Sd}$ & & & & \\
\hline Pardosa sp. & $\mathrm{Sr}$ & & & & \\
\hline Xerolycosa miniata (C.L. Koch, 1834) & $\mathrm{E}$ & $\mathrm{r}$ & $\mathrm{e}$ & $\mathrm{sr}$ & $\mathrm{d}$ \\
\hline Xerolycosa nemoralis (Westring, 1861) & $\mathrm{Sr}$ & & $\mathrm{sr}$ & $\mathrm{e}$ & $\mathrm{r}$ \\
\hline Trochosa terricola Thorell, 1856 & $\mathrm{Sr}$ & & & & \\
\hline
\end{tabular}

These tables show that the most common and widespread species of wolf spiders in the study area are Alopecosa accentuata, Alopecosa cuneata and Xerolycosa miniata. Slopes and terraces of reclaimed dumps of different ages and the control site of grassy-cereal meadows adjacent to the dumps are also inhabited by Pardosa bifasciata and Pardosa cf. lugubris. However, these species are few in number and are not a part of the dominant complexes, except for the second species, which is an eudominant on the terrace of a 15year-old dump (2nd site). It is also obvious that Pardosa agrestis meets favorable conditions on the heaps of the early succession stages. This species is typical for open warmed biotopes, which is more than a third of the spiders' population on the slope of the 15-yearold coal dump. On the control site, though, the proportion of this species does not reach $1 \%$. Pardosa prativaga, which is characterized as an eutytopic speciment, is noted exclusively on the slope of the 15-year-old dump. A larger species of Alopecosa uiensis, on the other hand, inhabits the slopes and terraces of later age dumps, in which it is included in the complexes of dominants as well as in the control area. Speaking in general about the species composition of Lycosides on the slope of the 15-year-old dump, it is important to note an ecologically very heterogeneous range of species. Here were found both forest dwellers (Alopecosa accentuata, Pardosa lasciva, Trochosa terricola, Xerolycosa nemoralis) and common species of steppe and other open biotopes (Pardosa agrestis, Pardosa bifasciata, Xerolycosa miniata). However, more numerous were species typical for open or poorly forested habitats (Pardosa agrestis, Xerolycosa miniata). The proportion of juveniles 
in the sample from this site was about $8 \%$ (Fig. 2), and in general, a lower proportion of immature individuals in the 15-year-old dump sites compared to the 30 -year-old and control site should be stated.

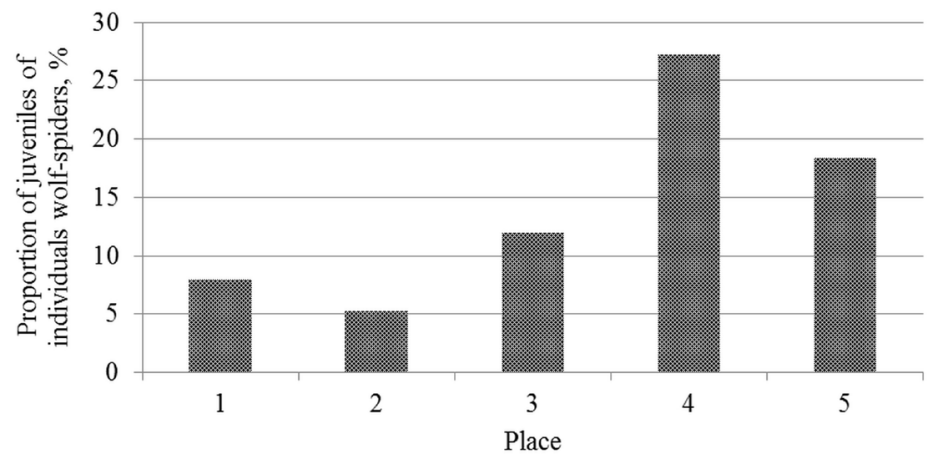

Fig. 2. The Proportion of juveniles of individuals wolf-spiders on the investigated place, $\%$.

The 15-year-old reclaimed dump located on the terrace, the second of the sites researched, is characterized by a good development of the herbage and a more humid substrate surface since there is no slope. The taxonomic diversity of Lycosides here was the lowest (Fig. 1), and the most abundant species was Pardosa cf. lugubris, which obviously found the most optimal living conditions at this site. The percentage of the superdominant on the slope of the 15-year-old dump (1st site) of Pardosa agrestis decreased sharply. The species becomes a subdominant. A similar reaction to the change in habitat conditions is demonstrated by Xerolycosa miniata, which was the part of the dominant complex as an eudominant on the slope. On the terrace, the species becomes a recedent, its percentage decreases from $20 \%$ to $1 \%$. The percentage of juveniles on this site was the lowest among all the sites studied and is just over 5\%, which was an additional evidence of the least favorable conditions of life for Lycosides in this habitat.

On the slope of the 30 -year-old dump (3rd site), woody scrub vegetation and a low herbage (projective cover 40-50\%) formed. Of the 11 species of wolf spiders recorded here, 6 are common for the slop of the 15-year-old dump (1st site), and the same number of common species is noted for the $3 \mathrm{rd}$ and 4 th sites. Only a few individuals of Pardosa fulvipes and Alopecosa pulverulenta were recorded exclusively on the slope of the 30-yearold dump. The former is typical for meadows, and the latter - for forests. The most abundant species in the 3rd site were Alopecosa cuneata and Xerolycosa miniata, inhabiting open or poorly afforested biotopes. The proportion of young individuals on the slope of the 30 -year-old dump is higher than on the slope of the 15-year-old dump, but more than twice lower than on the terrace of the 30 -year-old dump.

On the terrace of the 30-year-old reclaimed dump (site 4), the most numerous are Alopecosa uiensis and Xerolycosa nemoralis. Such species as Alopecosa sulzeri and Xerolycosa nemoralis are part of the dominants' complex only on this site. The proportion of juveniles here was the highest, among all the researched sites, including the control one. According to the number of Licoside species, the site on the terrace of the 30 -year-old dump is inferior to the site on the slope of the dump of the same age. The same pattern was observed for the terrace and the slope of the 15-year-old dump. However, the share of wolf spiders in the whole structure of the spiders' taxocene is twice as large as on the terrace of the 15-year-old dump and is close to the control site in terms of this parameter.

The control site, which is a birchwood, surrounded by forb meadows, is inhabitted by 
the species that occur on dumps of different ages. Nine out of 11 species are found in at least three of the sites examined. The most numerous are Alopecosa cuneata and Xerolycosa miniata - inhabitants of open biotopes, which inhabit slopes and terraces of dumps of different ages. The latter species is most abundant on the slopes of dumps of different ages. A number of typical species for forests, such as Trochosa terricola, Pardosa palidicola, Pardosa palustris and Pardosa lasciva, were not recorded at the control site but noted only on the slope of the 15-year-old dump.

In most habitats, four types of wolf spiders were included in the dominant complexes, except for the site on the terrace of a 15-year-old dump, where there were 3 such species.

Seasonal dynamics of species composition and dynamic density of spiders of th Lycosidae family on the dumps of different ages and the control site is shown in Fig. 3.

Studies have shown that the largest number of species of Lycosidae family on the slopes of dumps of different ages were found at the end of June, while on the terraces of coal dumps the maximum number of species of these spiders was found in the first half of June. In the first half of August, the activity of the specimens of this group is everywhere decreasing, and only adults of species of the genus Xerolycosa and juveniles Alopecosa and Pardosa occur in the traps. The activity of lycoside on the control site is somewhat longer, at least 3 species of wolf spiders are noted there in early August.

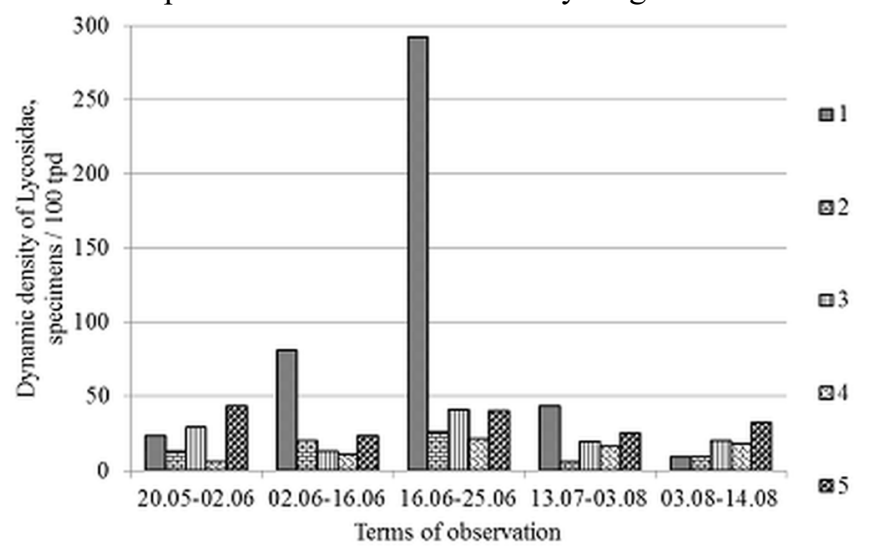

Fig. 3. Seasonal dynamics and changes of dynamic density of Lycosidae at the dumps and on control zone (Note: 1-5 - the investigated places)

The highest dynamic density of wolf spiders on the slopes and terraces of the reclaimed dumps has been recorded in the second half of June (Fig. 3). The peak of activity of Lycosidae was particularly stated on the slope of the 15-year-old heap, where the dynamic density was close to 300 specimens per 100 trap-days during this period.

In the control site, changes in dynamic density can be characterized as periodic fluctuations ranging from 23 to 43 specimens per 100 traps per day during the activity period. In general, this parameter was more stable at the control site and had a higher value in early August than on the slopes and terraces of the dumps.

\section{Conclusion}

As a result of the study, 20 species of wolf spiders belonging to 4 genera were found on the reclaimed cut dumps of the Krasnobrodsky coal mine and control area, they exceed all other species of spiders by taxonomic diversity in the research area. The most taxonomically diverse and numerous are wolf spiders on the slope of the 15-year-old dump where the 
percentages of both individuals and species of Lycosidae had the highest values.

The most common and widespread species of wolf spiders in the study area are Alopecosa accentuata, Alopecosa cuneata, and Xerolycosa miniata.

It was established that the proportion of immature individuals in the reclaimed dump sites of the 15-year-old age was lower than in the 30-year-old and control area.

The largest number of Lycosidae family species on the slopes of dumps of different ages occurred at the end of June, while on the terraces of coal dumps the maximum number of these spiders species during the season was observed in the first half of June.

The highest dynamic density of wolf spiders on the slopes and terraces of the reclaimed dumps has been recorded in the second half of June.

\section{Acknowledgement}

The reported study was funded by RFBR and Kemerovo Region according to the research project № 13-04-98029 and 16-44-420211.

\section{References}

1. C. R. Neet, Rev. suisse zool. Hors serie, 5, 99-102 (1996)

2. J-P. Maelfait, F. Hendrickx, Proc. of the 17th Eur. Col. of Arachn., 1, 293-300 (1998)

3. J. Rainio, J. Niemelä, Biodivers. Conserv., 12, (2003)

4. S. K. Stebaeva, V.S. Andrievsky, Rus. J. of Zool. 76, 9 (1997)

5. N. I. Eremeeva, S.L. Luzyanin, M.R. Kortchagina, S.V. Blinova, Izvestia Sankt Peterburgskoj Lesotehniceskoj Akademii, 207, 56-67 (2014)

6. S. L. Luzyanin, R.Yu. Dudko, A.N. Bespalov, N.I. Eremeeva, Euroasian Entomol. J., 14, 5 (2015)

7. N. I. Eremeeva, S.L. Luzyanin, Tomsk St. Univ. J. Biol., 39, (2017)

8. S. Luzyanin, N. Eremeeva, E3S Web Conf.., 21, 02014 (2017)

9. B. Ch. Sugiarto, D.Mardji, Biodivers., 17, 1 (2016)

10. M. Brändle, W. Durka, M. Altmoos, Biodivers. Conserv., 9, 8 (2000)

11. S. Pekár, Arachn. Mitt., 14, 34 (1997)

12. U. M. Ratschker, J. Meier, A. Wetzel, Arachn. Mitt., 29, 88-91 (2005)

13. M. Wozny, Acta Univ. Wratislav., 1, 1124, (1992) 